\title{
High Throughput 600 Watt Hall Effect Thruster for Space Exploration
}

\author{
James Szabo ${ }^{1}$, Bruce Pote, ${ }^{2}$ Rachel Tedrake, ${ }^{3}$ Surjeet Paintal, ${ }^{4}$ Lawrence Byrne,${ }^{5}$ Vlad Hruby, ${ }^{6}$ \\ Busek Co. Inc., Natick, MA, 01760, USA \\ Hani Kamhawi ${ }^{7}$, Tim Smith \\ NASA Glenn Research Center, Cleveland, Ohio, 44135
}

\begin{abstract}
A nominal 600-Watt Hall Effect Thruster was developed to propel unmanned space vehicles. Both xenon and iodine compatible versions were demonstrated. With xenon, peak measured thruster efficiency is $46-48 \%$ at $600-\mathrm{W}$, with specific impulse from $1400 \mathrm{~s}$ to 1700 s. Evolution of the thruster channel due to ion erosion was predicted through numerical models and calibrated with experimental measurements. Estimated xenon throughput is greater than $100 \mathrm{~kg}$. The thruster is well sized for satellite station keeping and orbit maneuvering, either by itself or within a cluster.
\end{abstract}

$\begin{array}{ll} & \\ \vec{B} & =\text { magnetic field } \\ \vec{E} & =\text { electric field } \\ g_{0} & =\text { gravitational constant at Earth's surface, } 9.81 \mathrm{~m} / \mathrm{s}^{2} \\ I_{d} & =\text { discharge current } \\ I_{s p} & =\text { specific impulse } \\ \dot{m} & =\text { mass flow rate } \\ P_{d} & =\text { discharge power } \\ r & =\text { radial direction or distance } \\ T & =\text { thrust } \\ V_{d} & =\text { discharge potential } \\ z & =\text { axial direction or distance } \\ \eta & =\text { efficiency } \\ \sigma & =\text { standard deviation }\end{array}$

\section{Introduction}

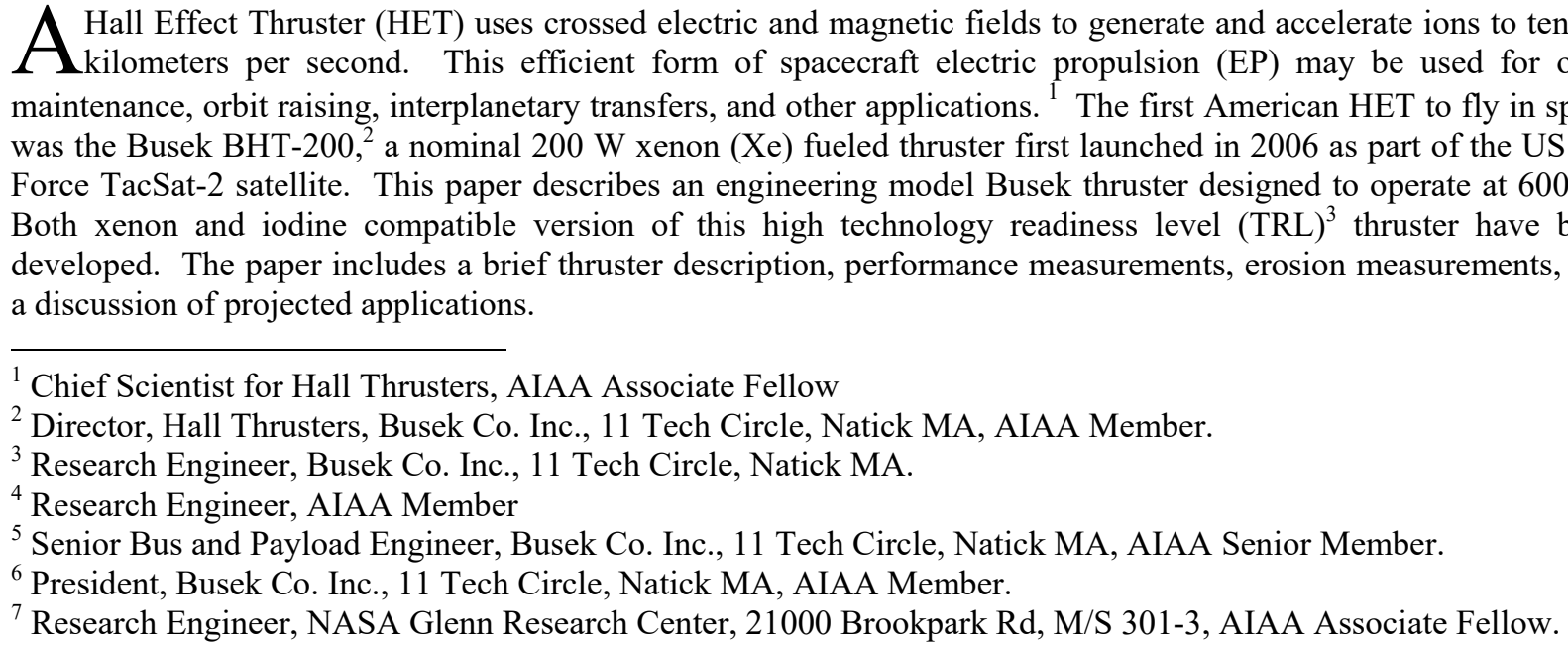

American Institute of Aeronautics and Astronautics 


\section{Apparatus and Procedures}

\section{A. Engineering Model Xenon Thruster System}

The BHT-600 was designed to operate at $600 \mathrm{~W}$, but is highly throttle-able in power and specific impulse. The mean diameter of the axisymmetric discharge channel is $56 \mathrm{~mm}$. A hollow cathode located distal to the channel provides electrons to seed the discharge and neutralize the ion beam. Electrical isolation of the anode from the flow path is achieved with a high voltage ceramic break of the type described in Ref. 4. At $600 \mathrm{~W}$ and a discharge potential of $300 \mathrm{~V}$, nominal thrust is $39 \mathrm{mN}$ and specific impulse is $1500 \mathrm{~s}$. Other top level specifications are found in Table 1

Figure 1 is a conceptual cross section of the thruster design. The magnetic field is driven by electromagnets. The upstream portion of the discharge channel is metallic, and the downstream portion of the discharge channel is dielectric. The metallic portion of the discharge channel shunts a portion of the magnetic field, creating a magnetic lens with a steep axial gradient in $|B|$ and near zero $|B|$ close the anode. ${ }^{5}$ A lens shape focuses ions away from the channel walls, promoting high efficiency and low channel erosion rates. ${ }^{6,7}$

Testing of the breadboard model BHT-600 in both individual and clustered configurations has been reported. Published research discusses thermal characterization, ${ }^{8}$ performance measurements, ${ }^{9}$ discharge oscillations, ${ }^{10}$ erosion modeling, ${ }^{11}$ plume characterization, ${ }^{12,13,1415,16}$ and the ion

\section{Table 1 Top Level Specifications for Xenon} Fueled Thruster

\begin{tabular}{cc}
\hline \hline Parameter & Value \\
\hline Discharge Potential & $200 \mathrm{~V}-400 \mathrm{~V}$ \\
Discharge Power Range & $200 \mathrm{~W}-800 \mathrm{~W}$ \\
Nominal Power & $600 \mathrm{~W}$ \\
Thrust* & $39 \mathrm{mN}$ \\
Specific Impulse* & $1500 \mathrm{~s}$ \\
Cathode Location & External \\
Thruster Mass & $2.6 \mathrm{~kg}$ \\
Cathode Mass & $0.2 \mathrm{~kg}$ \\
\hline \hline
\end{tabular}

${ }^{k}$ Xe propellant, $300 \mathrm{~V}, 600 \mathrm{~W}$ velocity distribution. ${ }^{17,18}$

In moving from the breadboard model to the engineering model, the magnetic field was modified to push the plasma discharge downstream, substantially increasing thruster lifetime. The mechanical structure was also heavily modified. The engineering model thruster has only been reported once before, in association with a NASA deep space exploration concept. ${ }^{19}$

The xenon fueled engineering model is supported by a flight model hollow cathode featuring a BaO-W electron emitter. This cathode has flown on the FalconSat-5 and FalconSat-6 spacecraft. The thruster is also supported by a flight heritage Power Processing Unit (PPU) and a newer compact PPU that is under development.

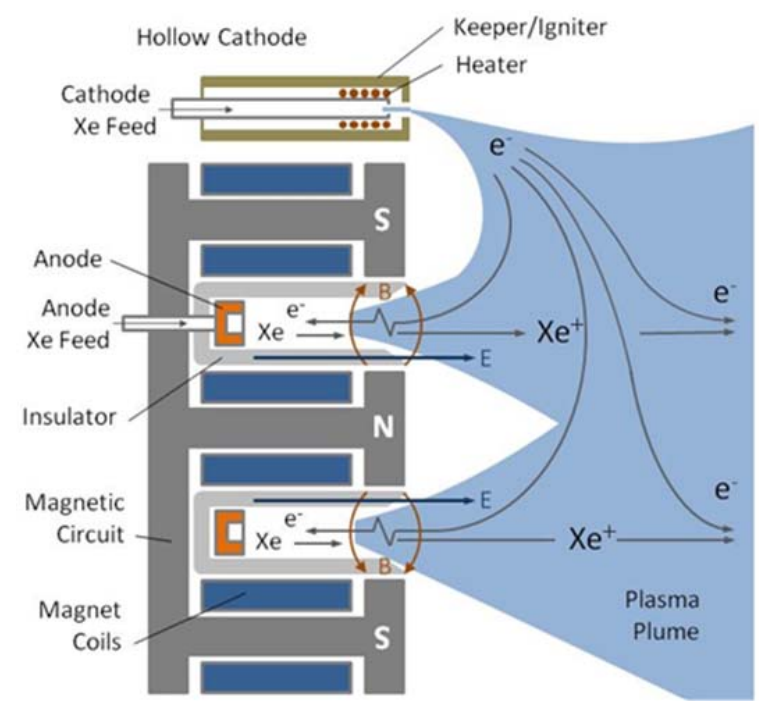

Figure 1. Nominal axisymmetric Hall Effect Thruster geometry (not to scale)

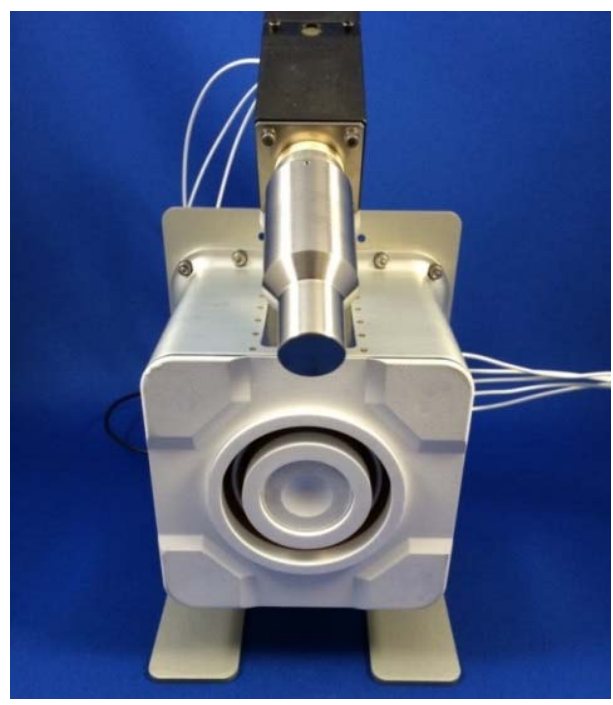

Figure 2 Iodine Compatible BHT-600-I Engineering Model Thruster on Test Bracket 

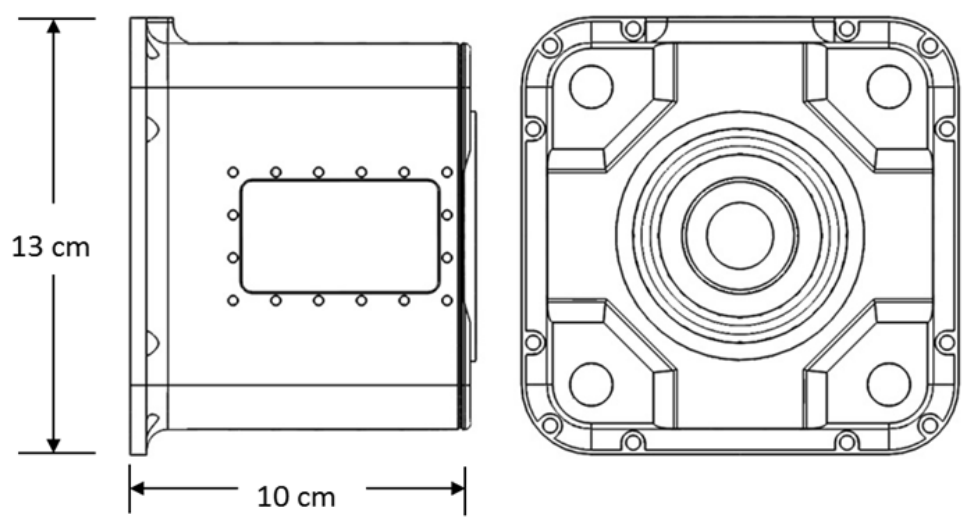

Figure 3 External Dimensions of BHT-600-I Engineering Model

\section{B. Iodine Compatible Thruster System}

An iodine compatible version of the BHT-600 engineering model is also being developed. This is known as the BHT-600-I. Iodine offers similar performance to xenon, but solid phase iodine $\left(\mathrm{I}_{2}\right)$ may be stored at low pressure yielding many system and mission benefits. ${ }^{20,21}$ In space, iodine vapor may be generated through sublimation by heating the propellant tank to modest temperatures. The vapor production and flow rate may be metered by multiple means including feedback control. ${ }^{22}$ Because iodine is a halogen, it is relatively reactive with some of the materials with which the BHT-600 was constructed. The BHT-600-I design addresses this issue though materials selection and coatings. However, the dimensions of the magnetic circuit and discharge channel are essentially unchanged from the BHT-600. Figure 2 shows the BHT-600-I along with a hexaboride $\left(\mathrm{LaB}_{6} \mathrm{or}^{\mathrm{CeB}}\right)_{6}$ cathode. Figure 3 identifies key external thruster dimensions.

In related work, an iodine compatible version of the BHT-200 is being developed for NASA's iodine satellite (iSat) technology demonstration mission. ${ }^{23,24,25}$ The top-level objectives of the project are focused on validating the use of iodine for future missions while demonstrating high $\Delta \mathrm{V}$ viability on a secondary small spacecraft. The system is scheduled for launch readiness in 2017.

An iodine fueled ion thruster demonstration is also planned. NASA's Lunar IceCube program will send a $6 \mathrm{U}$ CubeSat to search for signs of ice in the lunar regolith. The spacecraft will be equipped with Busek's BIT-3 RF ion thruster fueled by iodine. ${ }^{26}$ The system is scheduled to be launched as a secondary payload on the Space Launch System's maiden flight (SLS EM-1 mission) in 2018.

\section{Performance Mapping with Xenon}

The BHT-600 was performance tested with xenon in Busek's cryo-pumped T8 vacuum chamber, shown in Figure 4 (left), which has a nominal Xe pumping speed of $200,000-1 / \mathrm{s}$ and a base pressure in the $10^{-7}$ Torr regime. This facility has a diameter of 2.4-m and a length of 5-m. Background pressure was measured with an ion gauge located on the wall of the facility. Additional testing took place in Busek's 1.8-m diameter T6 facility. The discharge was powered by a $1000-\mathrm{V}, 10-\mathrm{A}$ power supply and the cathode allowed to float with respect to facility ground. A capacitor bank was typically placed in parallel with the discharge to filter oscillations. The inner and outer solenoid circuits were driven by separate DC power supplies independent of the discharge. Figure 4 (right) is a nominal power supply diagram. Additional testing was carried out with a breadboard PPU.

Xenon was fed with a calibrated feed system based upon Commercial Off-The-Shelf (COTS) mass flow controllers. Thrust, $T$, was measured with an inverted pendulum, "Null" type thrust stand corrected for thermal drift. $^{27}$

Specific impulse, $I_{s p}$, is determined from thrust and mass flow rate, $\dot{m}$, by the equation

$$
I_{s p}=T / \dot{m} g_{0} .
$$

Here, $g_{0}$ is the force of gravity on the surface of Earth. Anode $I_{s p}$ is calculated using only anode flow rate, $\dot{m}_{a}$. 

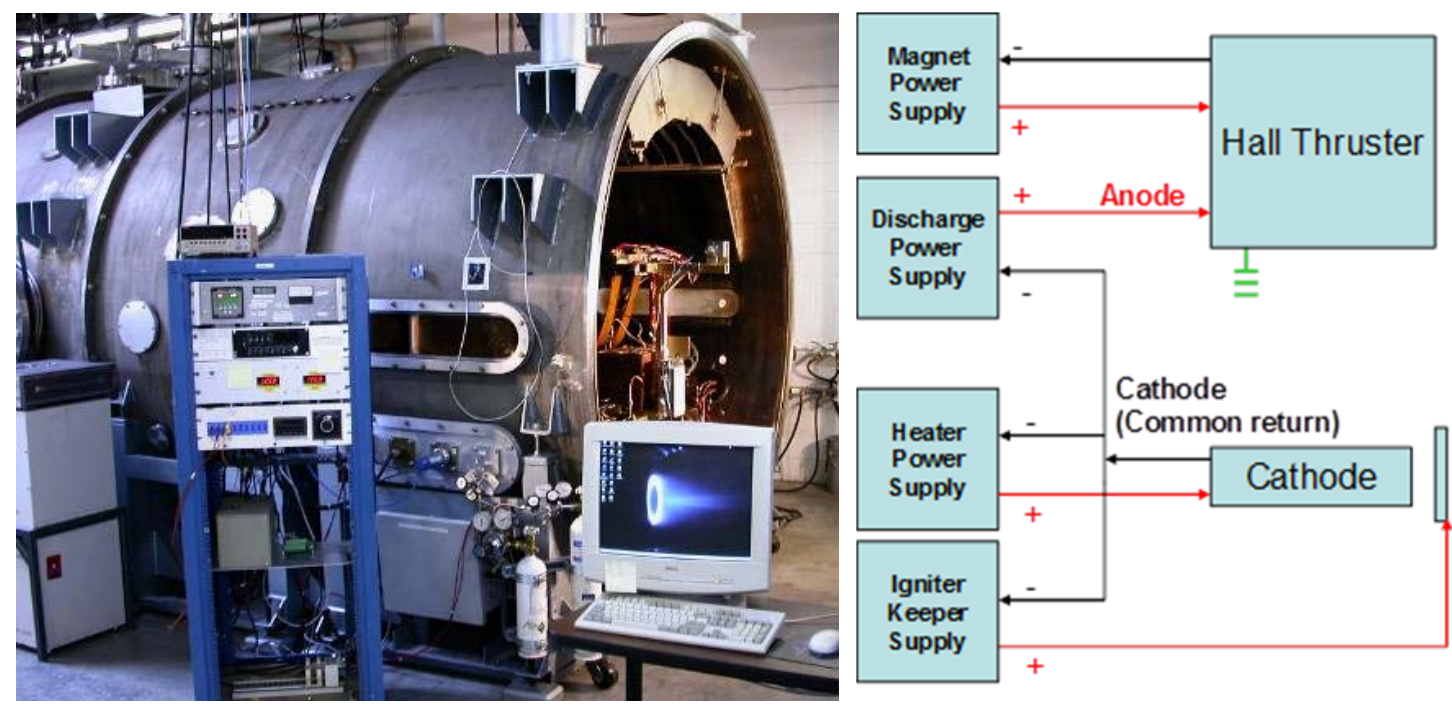

Figure 4. T8 test facility and nominal power supply diagram.

Total thruster efficiency is determined from $T, \dot{m}$, and the power provided to the thruster, $P$, through the equation

$$
\eta=T^{2} / 2 \dot{m} P .
$$

In Equation 2, $P$ includes the power provided to the discharge $\left(P_{d}=V_{d} I_{d}\right)$, electromagnets, and cathode. At the system level, PPU losses would also be included.

\section{Accelerated Lifetime Testing and Modeling}

The lifetime of Hall thrusters has historically been limited by erosion of the discharge channel caused by ion impact. The erosion rate is known to be a function of wall material, ion flux, ion energy, and, most importantly, the magnetic field shape. Boron nitride and boron nitride composites have been found to erode at a slow rate in the discharge channel, leading to their general use in Hall thrusters with dielectric channels.

To verify the lifetime of the BHT-600 is sufficient to meet mission needs, erosion testing was accomplished at NASA GRC using the original xenon propellant engineering model. Measurements were taken in GRC's Vacuum Facility 8 (VF8), shown in Figure 21. The physical dimensions are: $1.5 \mathrm{~m}$ diameter $\mathrm{x} 4.5 \mathrm{~m}$ long; with a $1.3 \mathrm{~m} \times 4.3$ isolated access chamber section. The

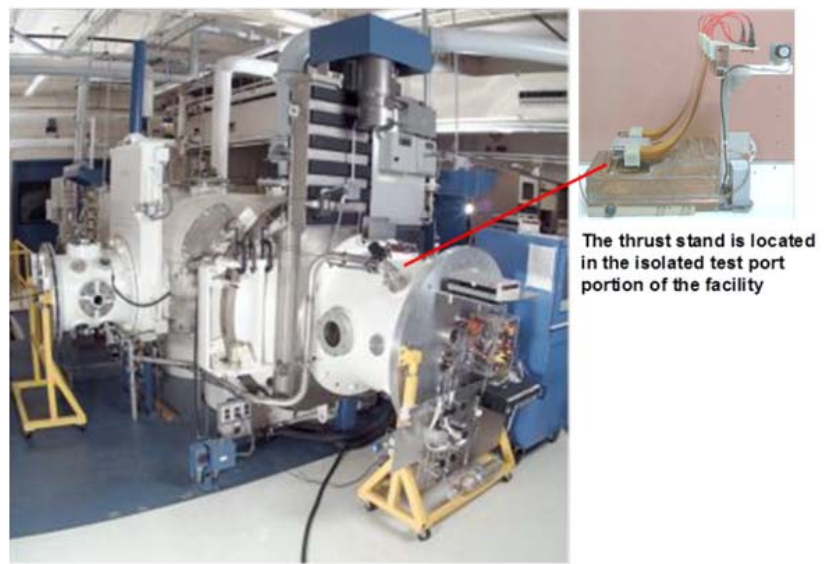

Figure 5. GRC's VF8 Facility where Erosion and Performance Measurements were Taken

facility pumping uses diffusion pumps with a pumping speed of 1.2x105 1/s @ 10-5torr (air) and an ultimate pressure (No Load) of $4 \times 10^{-7}$ Torr. This facility is equipped with an inverted pendulum thrust stand similar to the one at Busek. The thruster was powered both with laboratory power supplies and with a breadboard PPU.

In place of running the thruster for over a year, Busek and GRC conducted an accelerated life test which combined periodic measurements with modeling. During an accelerated life test, the thruster is run for some specific period of time. The erosion which results is measured and used to calibrate an erosion model, which is then stepped forward in time. The channel is then machined to match the predictions of the thruster erosion model and the process is repeated. The accelerated life test methodology is illustrated in Figure 6. Erosion rates were predicted with a Busek proprietary semi-empirical model that evolves the channel profile in time. 


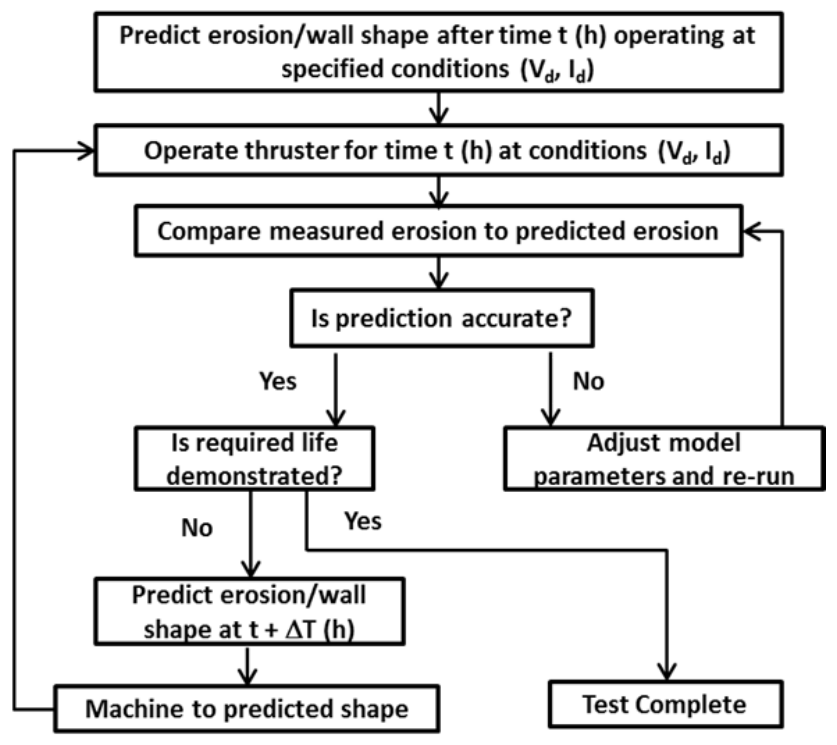

Figure 6 Accelerated Lifetime Methodology

\section{E. Iodine Testing}

The iodine fueled system was tested in NASA GRC's Vacuum Facility 7 (VF7), an oil diffusion pump evacuated facility that is $3 \mathrm{~m}$ in diameter and $4.6 \mathrm{~m}$ long. This facility has been modified for compatibility with iodine propellant. During nominal operations VF7 can reach back-pressures of $2 \times 10^{-7}$ Torr and for a thruster flow rate of 30 sccm the facility reaches a pressure of $3 \times 10^{-5}$ Torr (uncorrected). Liquid nitrogen cooled chevrons are used to collect the iodine propellant during thruster firing. After test completion, specially installed heating lamps are used to elevate the chevron temperatures to facilitate iodine propellant venting. Iodine vapor is vented through a dedicated line.

Iodine was provided by a custom feed system based upon the sublimation of iodine crystals in a heated upstream reservoir. The feed system setup provides for the option of operating the thruster with xenon or iodine propellants. ${ }^{25}$ The nominal configuration included a proportional flow valve built by VACCO Industries.

Thrust in VF7 was measured with inverted pendulum thrust stand. ${ }^{27}$ Additional details are found in Ref. 25.

\section{Results}

\section{A. BHT-600 Performance Measurements}

The initial configuration of the BHT-600 had a BaO-W cathode positioned to the side of the thruster, as shown in Figure 7. However, testing revealed that this position was not optimal for performance. Thus, the cathode was mounted upon a two-axis translation stage and its position in the horizontal and vertical directions was varied while thrust and other quantities were measured. Measurements showed that the floating voltage decreased as the distance from the front thruster face increased. The floating voltage also varied with distance from the thruster centerline. The anode efficiency generally increased the further downstream the cathode was placed (up to $\sim 2.3 \mathrm{~cm}$ ). However, placing the cathode far downstream or close to the centerline puts it in the path of primary (energetic) beam ions, which causes erosion of the keeper. This can also be a life limiting mechanism. Busek determined that a cathode position that balances thruster performance and keeper erosion was approximately $1.3 \mathrm{~cm}$ downstream from the thruster face and between $0.4-0.9 \mathrm{~cm}$ inward from the outside edge of the thruster face. This distance is measured from the bottom perimeter edge of the keeper tip. 


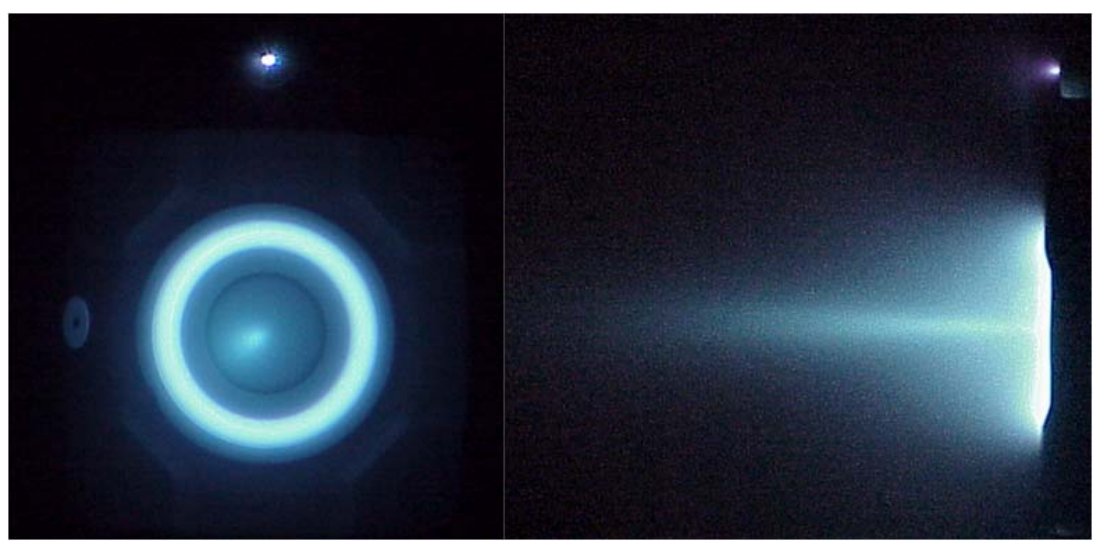

Figure 7 BHT-600 Engineering Model

The performance of the BHT-600 Engineering Model (EM) with the external cathode in the optimized position was measured in Busek's T8 test facility with the thruster powered by a breadboard power processing unit. Parameters modified during the course of the test included discharge voltage, anode gas flow rate, cathode gas flow rate, and magnet current. Figure 8 plots measured thruster efficiency against total specific impulse. Included data were taken at discharge potentials ranging from $200 \mathrm{~V}$ to $400 \mathrm{~V}$. The power calculation includes the discharge and the magnets. The propellant mass flow calculation includes both the anode and cathode. The efficiency of the PPU is not included. These measurements indicate that the EM thruster is slightly more efficient than the BM thruster at low power, but slightly less efficient at high power. Table 2 compares the performance of the two thrusters at a discharge potential of $300 \mathrm{~V}$. Some of the difference may be due to modifications to the magnetic field, cathode position, and discharge channel wall geometry. In the BM thruster, the downstream portion of the channel was chamfered to simulate the effects of erosion. In the EM thruster, the channel was not chamfered, simulating a beginning of life (BOL) configuration.

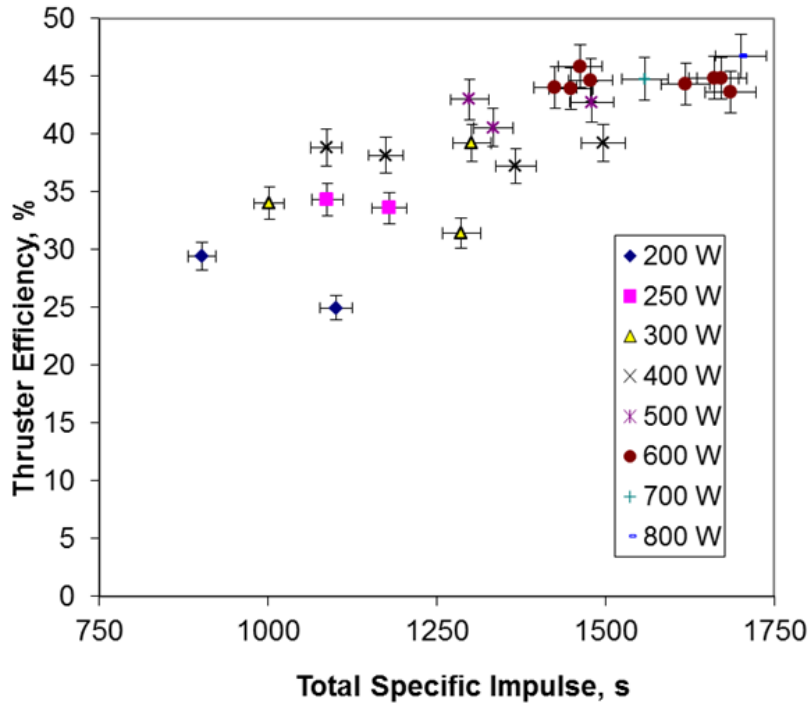

Figure 8 Total Efficiency vs. Total Specific Impulse for BHT-600 engineering model

Table 2 Comparison of BM and BOL EM Performance $\left(V_{d}=300 \mathrm{~V}\right)$

\begin{tabular}{cccccc}
\hline \hline $\begin{array}{c}\text { Thruster } \\
\text { Model }\end{array}$ & $\begin{array}{c}\text { Total } \\
\text { Power } \\
{[\mathbf{W}]}\end{array}$ & $\begin{array}{c}\text { Measured } \\
\text { Thrust } \\
{[\mathbf{m N}]}\end{array}$ & $\begin{array}{c}\text { Total } \\
\text { Isp } \\
{[\mathbf{s}]}\end{array}$ & $\begin{array}{c}\text { Total } \\
\text { Thruter Eff. } \\
{[\%]}\end{array}$ & $\begin{array}{c}\text { Thrust to } \\
\text { Power } \\
{[\mathrm{mN} / \mathbf{k W}]}\end{array}$ \\
\hline BM & 234 & 12.3 & 1179 & 30 & 53 \\
EM & 243 & 14.1 & 1180 & 34 & 58 \\
\hline BM & 301 & 17.1 & 1306 & 36 & 57 \\
EM & 322 & 19.8 & 1302 & 39 & 61 \\
\hline BM & 427 & 26.2 & 1431 & 43 & 61 \\
EM & 458 & 28.4 & 1334 & 41 & 62 \\
\hline BM & 616 & 40.8 & 1554 & 50 & 66 \\
EM & 609 & 38.9 & 1463 & 46 & 64 \\
\hline \hline
\end{tabular}




\section{B. BHT-600 Erosion Measurements and Life Test Predictions}

Thruster performance was characterized at NASA GRC near the beginning of erosion testing. The cathode was placed approximate to the optimized position. Measured performance was close to that obtained earlier at Busek under similar test conditions, as documented in Table 3.

To begin the life test, the thruster was first run for approximately $400 \mathrm{~h}$. The eroded walls of the discharge chamber were then compared to numerical predictions, and Busek's semi-empirical erosion model was calibrated. The model was then stepped forward to $1600 \mathrm{~h}$ and the channel was machined to the predicted profile. Next, the thruster was run for an additional $400 \mathrm{~h}$, the " $2000 \mathrm{~h}$ " channel was compared to numerical predictions, and the model was recalibrated. The model was then extrapolated to end of life, assumed to be the point where ion erosion reaches the magnet poles. The program concluded that a conservative prediction (factor of 2 margin) of the total operating time exceeds 10,000 h. Measured and predicted channel profiles using Busek's semi-empirical erosion model are shown in Figure 9.

Table 3 Comparison of BOL EM Thruster Performance Busek and GRC $\left(V_{d}=300 \mathrm{~V}\right)$

\begin{tabular}{cccccc}
\hline \hline $\begin{array}{c}\text { Test } \\
\text { Venue }\end{array}$ & $\begin{array}{c}\text { Total } \\
\text { Power } \\
{[\mathbf{W}]}\end{array}$ & $\begin{array}{c}\text { Measured } \\
\text { Thrust } \\
{[\mathrm{mN}]}\end{array}$ & $\begin{array}{c}\text { Total } \\
\text { Isp } \\
{[\mathbf{s}]}\end{array}$ & $\begin{array}{c}\text { Total } \\
\text { Thruter Eff. } \\
{[\%]}\end{array}$ & $\begin{array}{c}\text { Thrust to } \\
\text { Power } \\
{[\mathrm{mN} / \mathbf{k W}]}\end{array}$ \\
\hline Busek & 458 & 28.4 & 1334 & 41 & 62 \\
GRC & 414 & 25.5 & 1420 & 43 & 62 \\
\hline Busek & 609 & 38.9 & 1463 & 46 & 64 \\
GRC & 603 & 37.6 & 1504 & 46 & 62 \\
\hline \hline
\end{tabular}

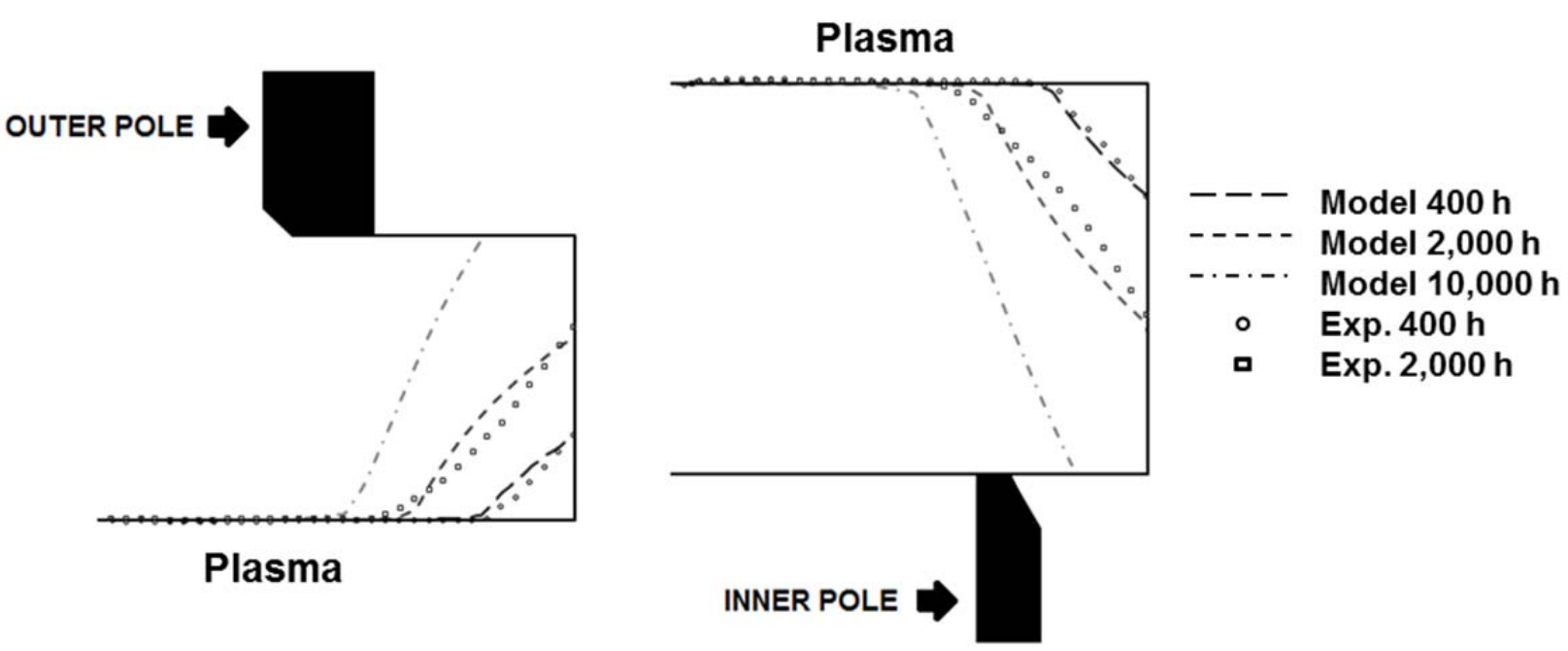

Figure 9 Measured Erosion Compared to the Model Predictions

\section{BHT-600-I Performance Measurements}

The BHT-600-I thruster and hexaboride emitter cathode were tested with xenon in Busek's T6 facility. For the data reported here, a cerium hexaboride $\left(\mathrm{CeB}_{6}\right)$ emitter was used. The cathode position was close to the optimized position found earlier. The thruster was powered by a breadboard version of the BPU-600 power processing unit, and the solenoids were run in series. The thrust stand was zeroed between each data point reported. Although the cathode floating voltage was greater in magnitude with the $\mathrm{CeB}_{6}$ cathode, the data nevertheless correlated well with earlier data taken with a $\mathrm{BaO}-\mathrm{W}$ cathode.

The cathode and thruster are shown together in Figure 10. Discharge oscillations at the $350 \mathrm{~V}$ operating point are shown in Figure 11. The magnitude is approximately $+/-1 \mathrm{~A}$, and the frequency is approximately $40 \mathrm{kHz}$. Performance data are reported in Table 4.

Preliminary characterization of the BHT-600-I took place with the channel in the BOL configuration (i.e. no chamfer). However, the thruster was delivered to GRC for iodine testing with a channel machined to the " $1600 \mathrm{~h}$ " profile determined in the BHT- 600 accelerated lifetime test. 


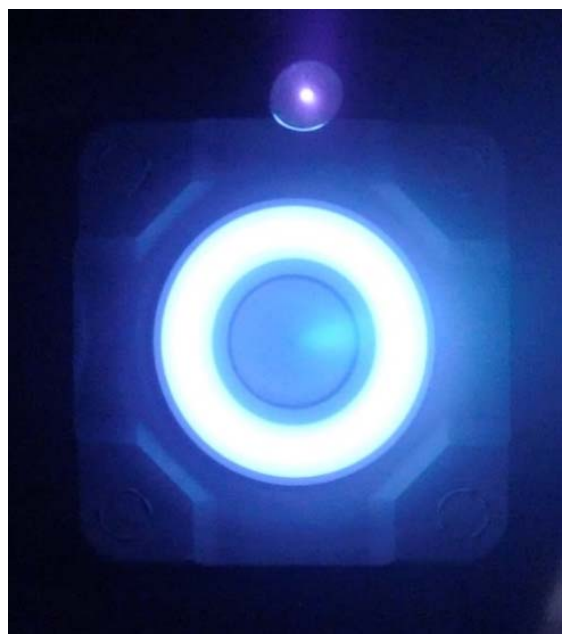

Figure 10 BHT-600-I firing with Hexaboride Cathode

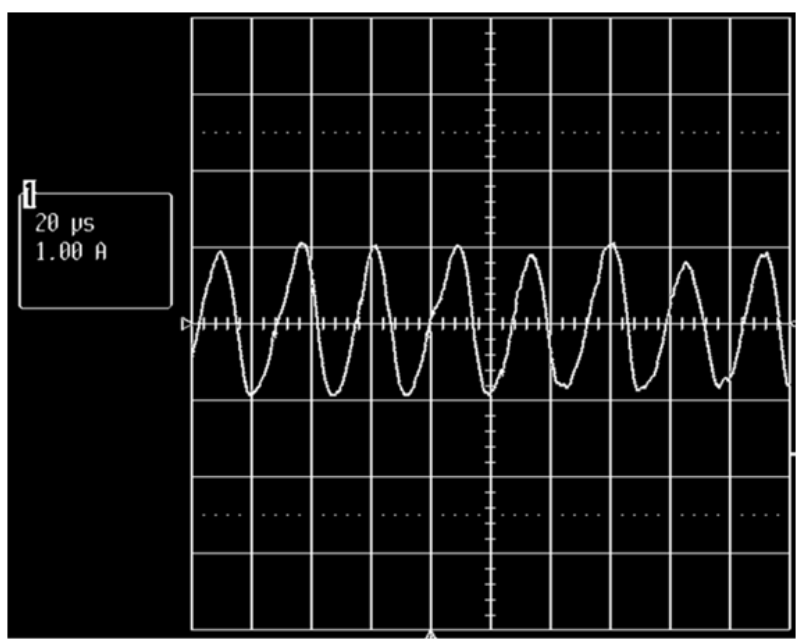

Figure 11 Discharge Current Oscillations from BHT600-I and $\mathrm{CeB}_{6}$ cathode

Table 4 BHT-600-I Performance on Xe with $\mathrm{CeB}_{6}$ Cathode and Preliminary Channel

\begin{tabular}{|c|c|c|c|c|c|c|c|c|c|c|c|c|c|c|}
\hline $\begin{array}{l}\text { Anode } \\
\text { Flow } \\
\text { Rate } \\
\text { [SCCM] } \\
\end{array}$ & $\begin{array}{l}\text { Cathode } \\
\text { Flow } \\
\text { Rate } \\
{[\mathrm{SCCM}]} \\
\end{array}$ & $\begin{array}{c}\text { Anode } \\
\text { Disharge } \\
\text { Voltage } \\
{[\mathrm{V}]}\end{array}$ & $\begin{array}{c}\text { Anode } \\
\text { Discharge } \\
\text { Current } \\
{[\mathrm{A}]}\end{array}$ & $\begin{array}{c}\text { In Series } \\
\text { Magnet } \\
\text { Voltage } \\
{[\mathrm{V}]}\end{array}$ & $\begin{array}{c}\text { In Series } \\
\text { Magnet } \\
\text { Current } \\
{[\mathrm{A}]}\end{array}$ & $\begin{array}{c}\text { Cathode } \\
\text { Floating } \\
\text { Voltage } \\
{[\mathrm{V}]}\end{array}$ & $\begin{array}{c}\text { Tank } \\
\text { Pressure }\end{array}$ & $\begin{array}{c}\text { Discharge } \\
\text { Power }\end{array}$ & $\begin{array}{l}\text { Total } \\
\text { Power }\end{array}$ & $\begin{array}{c}\text { Measured } \\
\text { Thrust } \\
{[\mathrm{mN}]}\end{array}$ & $\begin{array}{c}\text { Anode } \\
\text { Isp } \\
\text { [s] }\end{array}$ & $\begin{array}{l}\text { Total } \\
\text { Isp } \\
\text { [s] }\end{array}$ & $\begin{array}{c}\text { Anode } \\
\text { Thrust } \\
\text { Eff. } \\
{[\%]} \\
\end{array}$ & $\begin{array}{c}\text { Total } \\
\text { Thruster } \\
\text { Eff. } \\
{[\%]} \\
\end{array}$ \\
\hline 25.1 & 2.0 & 300 & 2.0 & 6.2 & 2.3 & -18.1 & $1.1 \mathrm{E}-05$ & 600 & 614 & 38.8 & 1618 & 1500 & 51 & 47 \\
\hline 29.6 & 2.1 & 250 & 2.4 & 6.3 & 2.3 & -15.0 & $1.2 \mathrm{E}-05$ & 600 & 614 & 42.6 & 1501 & 1403 & 52 & 48 \\
\hline 21.9 & 1.6 & 350 & 1.7 & 6.3 & 2.3 & -14.0 & $1.0 \mathrm{E}-05$ & 599 & 613 & 36.5 & 1740 & 1624 & 52 & 47 \\
\hline
\end{tabular}

\section{Iodine Testing}

The main objectives of the iodine test campaign were to evaluate the performance of the thruster with both xenon and iodine propellants, and to perform duration testing with iodine to uncover any degradation or change in thruster performance or component conditions due to extended exposure. Two duration tests were performed, totaling $80 \mathrm{~h}$. For both tests, the cathode was fed with Xe.

The first duration test lasted $34 \mathrm{~h}$. For this test, the BHT-600-I was configured with Busek's $\mathrm{CeB}_{6}$ emitter hollow cathode, and the $\mathrm{I}_{2}$ feed system included a proportional valve for fine control of the flow rate. Figure 12 shows the iodine plume during testing. Prior to the first duration test, performance was baselined with xenon at discharge power levels of $P_{d}$ $=200,300,400,500$, and $600 \mathrm{~W}$ and discharge potentials of $V_{d}=200,250$, and $300 \mathrm{~V}$. Then the

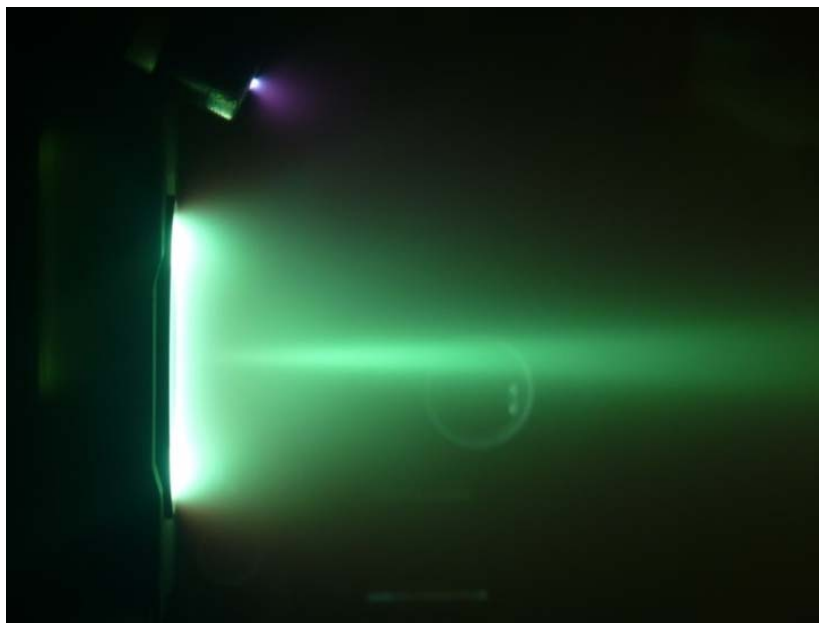

Figure 12 Iodine plasma plume from BHT-600-I during testing at GRC

thruster was run continuously for approximately $34 \mathrm{~h}$ at $V_{d}=300 \mathrm{~V}, I_{d}=2 \mathrm{~A}$. After exhausting all the $\mathrm{I}_{2}$ in the propellant tank $(0.3 \mathrm{~kg})$, thruster performance was re-evaluated with Xe and found to be unchanged. Table 5 summarizes measured thrust levels with $\mathrm{Xe}$ and $\mathrm{I}_{2}$ at the beginning and end of the 34 hour duration test. Estimated uncertainty in thrust is $2 \%$ of the measured value. The Xe performance also compares well to data taken earlier with the BHT-600 and BaO-W cathode when the channel was cut to the same "1600 h" profile. At that time, $I_{d}=1.97 \mathrm{~A}$ and $V_{d}=300 \mathrm{~V}$ returned $T=38.4 \mathrm{mN}$, which was the same thrust level measured at GRC. 
Table 5 Thrust levels at the beginning and end of 34 hour duration test with $\mathrm{Xe}$ and $\mathrm{I}_{2}$

\begin{tabular}{lcccc}
\hline \hline & \multicolumn{2}{c}{ Time $=\mathbf{0 ~} \mathbf{c}$} & \multicolumn{2}{c}{ Time $=\mathbf{3 4} \mathrm{h}$} \\
& Xenon & lodine & Xenon & lodine \\
\hline Discharge Potential [V] & 300 & 300 & 300 & 300 \\
Discharge Current [A] & 2.0 & 2.0 & 1.98 & 2.0 \\
Thrust [mN] & 38.4 & 39.2 & 38.4 & 38 \\
\hline \hline
\end{tabular}

The second duration lasted $46 \mathrm{~h}$. This time the BHT-600-I was configured with a $\mathrm{BaO}-\mathrm{W}$ insert cathode. In this case, the $I_{2}$ feed system did not include proportional valve for fine control; flow rate was instead controlled by regulating reservoir temperature. The thruster was run continuously at $V_{d}$ $=300 \mathrm{~V}$. The discharge current was maintained at approximately 2 A for most of the test. However, current dropped toward the end as the $I_{2}$ tank became depleted. After the $\mathrm{I}_{2}$ was exhausted, thrust was again measured with $\mathrm{Xe}$ and found to be unchanged.

\section{Discussion}

\section{A. Measurement Uncertainty}

Uncertainty associated with BHT-600 xenon performance measurements at Busek was estimated with standard methods. ${ }^{29}$ Table 6 summarizes the calculation for $P, T, \dot{m}$, $I_{s p}$, and $\eta$. The normalized standard deviation, $\sigma$, or uncertainty in $P$ is estimated to be $1 \%$. The uncertainty in $T$ is estimated to be $1.9 \%$. Contributions include the calibration curve, sample-to-sample signal variation, and thrust stand drift. The uncertainty in $\dot{m}$ is estimated to be $1.0 \%$. Contributions include uncertainties in the flow controller and estimated propellant backflow from the test facility. Still, it is possible that Table 6 underestimates the uncertainty associated with flow control as the factory calibration of the flow meter is assumed.

Uncertainties for specific impulse and efficiency from Table 6 are plotted on Figure 8. The normalized variance ( $\sigma^{2}$ in specific impulse is given by the equation

$$
\left(\frac{\sigma_{I_{s p}}}{I_{s p}}\right)^{2}=\left(\frac{\sigma_{T}}{T}\right)^{2}+\left(\frac{\sigma_{\dot{m}}}{\dot{m}}\right)^{2} .
$$

For the values in Table 6 , the uncertainty in $I_{s p}$ is $2.2 \%$. Thus if specific impulse is $1500 \mathrm{~s}$, the uncertainty is $+/-$ $33 \mathrm{~s}$. The normalized variance in efficiency, $\eta$, is

$$
\left(\frac{\sigma_{\eta}}{\eta}\right)^{2}=4\left(\frac{\sigma_{T}}{T}\right)^{2}+\left(\frac{\sigma_{\dot{m}}}{\dot{m}}\right)^{2}+\left(\frac{\sigma_{P}}{P}\right)^{2} .
$$

For the values above, the normalized uncertainty in $\eta$ is estimated to be $4.1 \%$. Thus, if measured efficiency is $50 \%$, the uncertainty is $+/-2 \%$.

\section{B. Flight System}

A complete flight propulsion system must include a propellant management system and a power processing unit (PPU). For near term, xenon fueled missions, a feed system developed for FalconSat-5 and FalconSat-6 is readily available. A BHT-600 based propulsion system could also include Busek's flight demonstrated BPU-600 PPU, which is capable of driving a Hall thruster discharge at any desired discharge potential up to $400 \mathrm{~V}$. Peak discharge current is $3 \mathrm{~A}$, for a total discharge power of $1200 \mathrm{~W}$. Its peak efficiency is $94 \%$, including all ancillary losses. The input potential is $28 \mathrm{~V}$. 
For iodine missions, the BHT-600-I may be fueled with a variant of the iSat feed system and powered by a $600 \mathrm{~W}$ version of the iSat PPU. Projected dimensions for Busek's $600 \mathrm{~W}$ compact PPU are $24 \mathrm{x}$ $16 \times 6 \mathrm{~cm}$. The layout is shown in Figure 13. The PPU accepts input voltages from 24-36 V and peak discharge potential is $400 \mathrm{~V}$. This PPU includes control of the iodine feed system components. Functionality includes the control of independent heater zones for the propellant lines, the tank heater, temperature sensors, and pressure transducers while also performing on-board closed-loop flow control based on either discharge current or a pressure

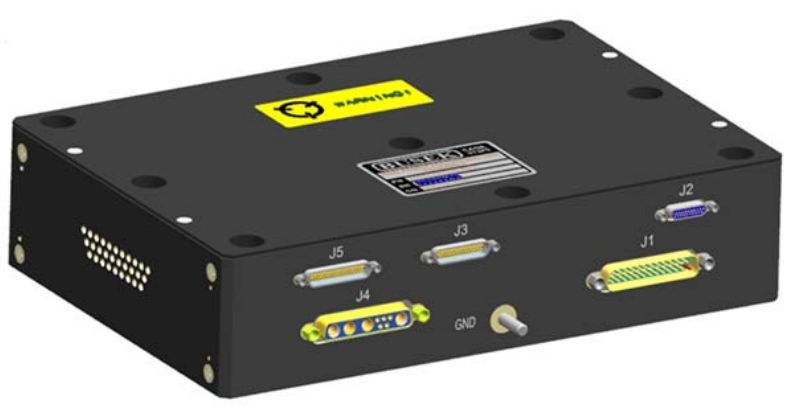

Figure 13 Compact PPU Layout measurement. The compact PPU uses an RS422 interface and has FPGA based control of outputs and telemetry. The $600 \mathrm{~W}$ compact PPU may also be used with the BHT-600 and other xenon thrusters.

\section{Mission Applications}

Applications for the BHT-600 and BHT-600-I include orbit maintenance, orbit raising, rephrasing, inclination changes and interplanetary transfers. Orbit maintenance includes N-S and E-W station-keeping for geosynchronous satellites, and drag make-up for low earth orbit satellites. On an all-electric satellite, the thruster could provide both orbit-raising to geosynchronous orbit and on-orbit station-keeping. Interplanetary applications are enabled by the high throughput of the BHT-600. Total throughput can be estimated from the conditions in Table 4. For the $300 \mathrm{~V}$ operating point ( $I_{s p}=1500 \mathrm{~s}$ ), if the mass flow rate is $2.6 \mathrm{mg} / \mathrm{s}$ and the lifetime is $10,000 \mathrm{~h}$ (believed to be conservative), the total propellant throughput is $95 \mathrm{~kg}$.

A throttle table for the thruster operating at $400 \mathrm{~W}$ and $600 \mathrm{~W}$ was constructed by assuming constant efficiency and limiting specific impulse to the demonstrated range of $1200 \mathrm{~s} \leq I_{s p} \leq 1700 \mathrm{~s}$. Efficiency and specific impulse determine thrust to power by

$$
T / P=2 \eta / I_{s p} g_{o} .
$$

To construct Table $7, \eta$ was assumed to be $42 \%$ at $400 \mathrm{~W}$ and $46 \%$ at 600 W. These values were drawn from Table 3. Because prior testing with other thrusters indicates that thruster efficiency with xenon and iodine propellants is nearly the same, this table may be used for both propellants.

Table 7. Xe Throttle Table

\begin{tabular}{ccc}
\hline \hline & \multicolumn{2}{c}{ Thrust [m N] } \\
Is $\mathbf{p}$ [s] & $\mathbf{P = 4 0 0 ~} \mathbf{~}$ & $\mathbf{P = 6 0 0 ~} \mathbf{~}$ \\
\hline 1200 & 28.5 & \\
1300 & 26.3 & \\
1400 & 24.5 & 38.4 \\
1500 & 22.8 & 35.9 \\
1600 & & 33.6 \\
1700 & & 31.7 \\
\hline \hline
\end{tabular}

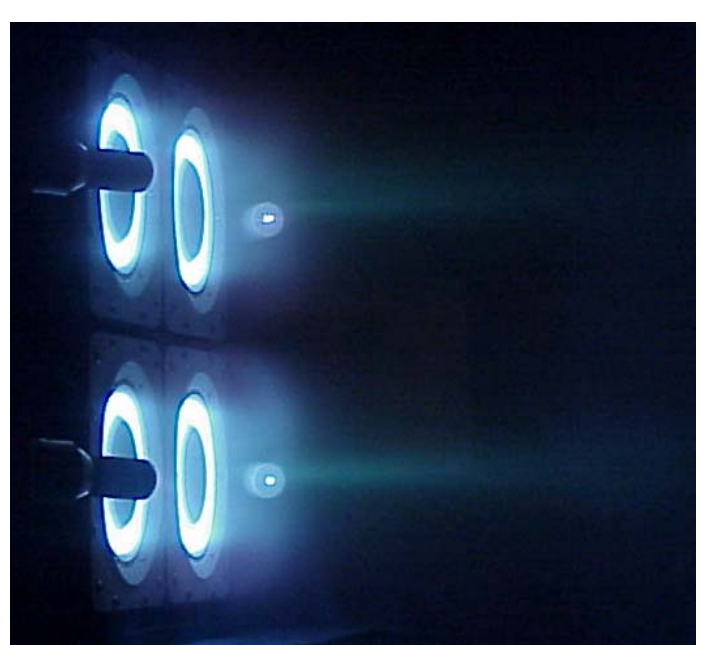

Figure 14. BM BHT-600 cluster.

Clustering the BHT-600 would enable its use for much higher power missions. In general, peak thruster efficiency increases monotonically with thruster size. However, as propellant utilization nears $100 \%$, other considerations such as thruster redundancy may outweigh incremental efficiency gains. A decade ago, the Air Force Research Laboratory (AFRL) initiated a program to cluster HETs. Sub-scale clusters of four were constructed using low-power Busek thrusters starting with the BHT-200 and proceeding to the BHT-600 breadboard model. Performance and plume measurements showed no detrimental effects from clustering these thrusters. ${ }^{9,30,31,32}$

Iodine fueled systems provide additional system and mission advantages. ${ }^{33,34}$ At typical storage conditions, e.g. 14$\mathrm{MPa}$ and 50 degrees- $\mathrm{C}$, the stored density of $\mathrm{Xe}$ is $1.6-\mathrm{kg} / \mathrm{l}$. At the same conditions, $\mathrm{Kr}$ stores at just $0.5-\mathrm{kg} / \mathrm{l}$. Iodine, on the other hand, stores in the solid phase, which has a density of 4.9-kg/l. Furthermore, iodine stores at very low pressure; the feed system pressure can me much less than one atmosphere. 


\section{Spacecraft System Concepts}

The USAF now mandates that all Evolved Expendable Launch Vehicle (EELV) launched with excess capacity include the EELV Secondary Payload Adapter (ESPA) ring carrying secondary payloads. To utilize this excess launch capacity, Busek is developing a secondary payload maneuvering system propelled by the BHT-600. Busek's Propulsion, Power and Attitude Control System (ProPACS) ${ }^{35}$ provides from 70 to $100 \mathrm{~kg}$ of payload mass (depending on system options) and over 150 liters of payload volume. The complete system including the payload fits within a standard $24 \times 28 \times 38$ " ESPA secondary payload envelope. The power and management distribution system is sized to meet the needs of both the propulsion system and payload. Nominal power at BOL is $1200 \mathrm{~W}$, supplied by articulating solar arrays and stored in batteries. The nominal propellant load is approximately $30 \mathrm{~kg}$ of Xe. Attitude control is provided by gimbals on the Hall thruster, torque rods, and optional xenon cold gas thrusters. Figure 15 shows the ProPACS attached to the ESPA (left) and approaching an asteroid or Near Earth Object (NEO) with a payload.
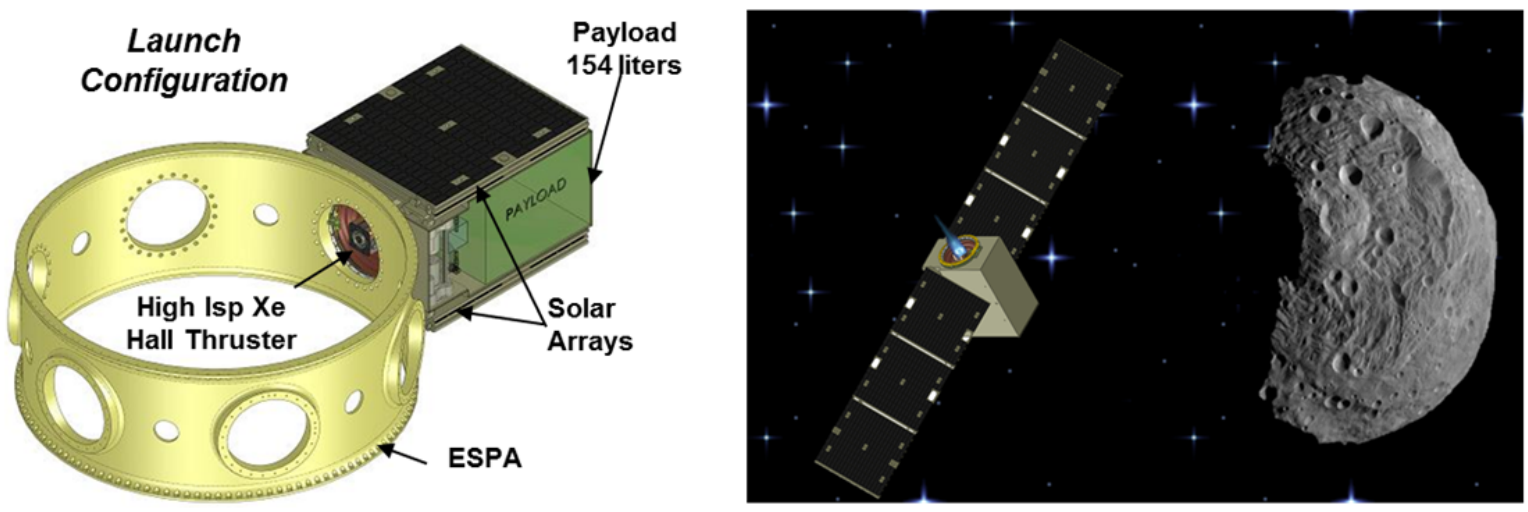

Figure 15. ESPA and Propulsion, Power and Attitude Control System (ProPACS)

A low cost asteroid or NEO exploration mission could be carried out with Busek's Unmanned Solar Electric Resource Prospector (USERP) concept, an iodine fueled system that is derived from ProPACS. After separation from the ESPA in a geostationary transfer orbit (GTO), a BHT-600-I would propel the USERP to an asteroid or other body of interest. Once the spacecraft has reached the destination, the Hall thruster may be used to conduct local maneuvers required for surveying and sensing the surface.

To achieve the $\Delta \mathrm{V}$ required reach asteroids and NEOs from GTO, the propellant load must be increased with respect to ProPACS. The available $\Delta \mathrm{V}$ is determined by the specific impulse of the thruster, the propellant mass, and the total system mass (including payload). Figure 16 plots available $\Delta \mathrm{V}$ against specific impulse for different payload mass fractions and thruster operating conditions. Assuming initial system mass is $180 \mathrm{~kg}$ and $I_{s p}$ $=1750 \mathrm{~s}$, a payload mass fraction of 0.7 (propellant mass of $54 \mathrm{~kg}$ ) yields $\Delta \mathrm{V}=6.0 \mathrm{~km} / \mathrm{s}$. In this figure, payload mass is everything that is not propellant.

If the initial mass is smaller, so is the propellant load. Students at Rensselaer Polytechnic Institute (RPI) designed a microsatellite spacecraft (wet mass $<35 \mathrm{~kg}$ ), mission profile and architecture to enable preliminary in-situ characterization of a significant number of Near Earth Objects (NEOs) at reasonably low cost. ${ }^{36}$ For propulsion, RPI's Near Earth Object Scout Spacecraft would carry an iodine fueled BHT-600.

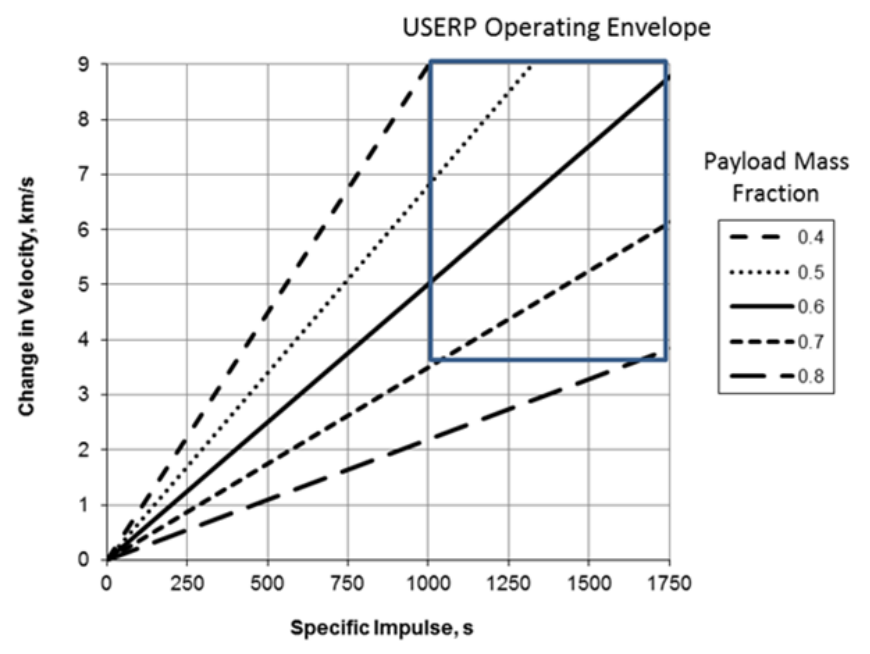

Figure 16 USERP Payload Mass and $\Delta V$ Trade 


\section{Conclusions}

With funding from NASA and the Air Force, Busek has developed a $600 \mathrm{~W}$ Hall Effect Thruster that has many potential in-space applications. Nominal specific impulse is $1500 \mathrm{~s}$ at $600 \mathrm{~W}$. Projected lifetime, based on the results of an accelerated life test, is greater than 10,000 hours. Both xenon and iodine compatible versions of the thruster are presently at TRL 5 or above.

\section{Acknowledgments}

The authors wish to acknowledge support from Ames Research Center under contract NNX10CA12C and Glenn Research Center under contract NNX13CC82C. The authors also wish to acknowledge Kennedy Space Center, which is funding USERP work under contract NNX15CK14P. Finally, the authors wish to acknowledge the many other people who contributed including Charlie Feng, Juraj Kolencik, Charles Freeman, Roy Martin, Walter Foxworth, Douglas Spence, Mike Dassau, Tom Roy, Roy Martin, Mark Young, and Peter Rostler.

\section{References}

1 Martinez-Sanchez, M., and Pollard, J., "Spacecraft Electric Propulsion - An Overview," Journal of Propulsion and Power, 1998, 14 (5), $688-699$.

2 Monheiser, J., Hruby, V., Freeman, C., Connolly, W., and Pote, B., "Development and Testing of a Low-Power Hall Thruster System" in Micropropulsion for Small Spacecraft, M. Micci and A. Ketsdever, Eds.; AIAA Progress Series in Astronautics and Aeronautics, Reston, VA., Vol. 187, 2000, pp. 244-269.

3 Mankins, J., "Technology Readiness Levels: A White Paper”, NASA, Office of Space Access and Technology, Advanced Concepts Office, April 1995.

4 Szabo, J., Pote, B., Byrne, L, Paintal, S., Hruby, V., Tedrake, R., Kolencik, G., Freeman, C. "Eight Kilowatt Hall Thruster System Characterization," Proceedings of the 33rd International Electric Propulsion Conference, Electric Rocket Propulsion Society, IEPC Paper 2013-317, The George Washington University, USA, October 6-10, 2013.

5 Busek Co. Inc., "Hall Field Plasma Accelerator with Inner and Outer Anode," U.S. Patent No. 6,075,321, 13 Jun 2000.

6 A. I. Morozov, Yu. V. Esipchuk, G. N. Tilinin, A. V. Trofimov, Yu. A. Sharov, G. Ya Shchepkin, "Plasma Accelerator with Closed Electron Drift and Extended Acceleration Zone," Soviet Physics - Technical Physics, 1972, 17 (1), 38-45.

7 A. I. Morozov, Yu. V. Esipchuk, A. M. Kapulkin, V. A. Nevrovskii, V. A. Smirnov, "Effect of the Magnetic Field on a Closed-Electron-Drift Accelerator," Soviet Physics - Technical Physics, 1972, 17 (3), 482-487.

8 Matlock, T., Hargus, W., Larson, C., "Thermographic Characterization and Comparison of 200W and 600W Hall Thrusters," 43rd AIAA/ASME/SAE/ASEE Joint Propulsion Conference \& Exhibit, 2007, 10.2514/6.20075241.

$9 \quad$ Lobbia, R., Gallimore, A., "Performance Measurements from a Cluster of Four Hall Thrusters," IEPC-2007177. 30th International Electric Propulsion Conference, Florence, Italy, Sep 17-20, 2007.

10 Lobbia, R., Gallimore, A., "Evaluation and Active Control of Clustered Hall Thruster Discharge Oscillations," 41st AIAA/ASME/SAE/ASEE Joint Propulsion Conference \& Exhibit. 10 July 2005 - 13 July 2005,

11 Cheng, S., and Martinez-Sanchez, M., "Hybrid Particle-in-Cell Erosion Modeling of Two Hall Thrusters," Journal of Propulsion and Power 2008 24:5, 987-998

12 Eckholm, J., Hargus, W., Larson, C., Nakles, M., Reed, G. and Niemela, C., "Plume Characteristics of the Busek 600 W Hall Thruster," 42nd AIAA/ASME/SAE/ASEE Joint Propulsion Conference \& Exhibit, 2006, $10.2514 / 6.2006-4659$

13 Lobbia, R., Gallimore, A., "A Method of Measuring Transient Plume Properties," 44th AIAA/ASME/SAE/ASEE Joint Propulsion Conference \& Exhibit., Publication Date: 21 July 2008 - 23 July 2008

14 Hargus, W., and Charles, C., "Near Plume laser Induced Fluorescence Velocity Measurements of a 600 W Hall Thruster," 44th AIAA/ASME/SAE/ASEE Joint Propulsion Conference \& Exhibit. July

Publication Date: 21 July 2008 - 23 July 2008

15 Bui, D. M., "Plume Characterization of Busek 600W Hall Thruster," MS Thesis, AFIT/GA/ENY/12-M05, March 2012.

16 Victor, A., Zurbuchen, T., Gallimore, A., "Ion-Energy Plume Diagnostics on the BHT-600 Hall Thruster Cluster," Journal of Propulsion and Power 2006 22:6, 1421-1424 
17 Nakles., M. and Hargus, W., "Background Pressure Effects on Ion Velocity Distribution Within a MediumPower Hall Thruster," Journal of Propulsion and Power 2011 27:4, 737-743

18 Hargus, W., Nakles, M., Tedrake, R., Pote, B., "Effect of Anode Current Fluctuations on Ion Energy Distributions within a $600 \mathrm{~W}$ Hall Effect Thruster," 44th AIAA/ASME/SAE/ASEE Joint Propulsion Conference \& Exhibit, 2008, 10.2514/6.2008-4724

19 Strange, N., Landau, D., Hofer, R., Snyder, J., Randolph, T., Campagnola, S., Szabo, J., and Pote, B., "Solar Electric Propulsion Gravity-Assist Tours for Jupiter Missions," 2012 AIAA/AAS Astrodynamics Specialists Conference, Minneapolis, MN, August 13-16, 2012.

20 Szabo, J., Pote, B., Paintal, S., Robin, M., Hillier, A., Branam, R., Huffman, R., "Performance Evaluation of an Iodine Vapor Hall Thruster", Journal of Propulsion and Power, Vol. 28, No. 4, pp. 848-857 (2012).

21 Szabo, J., Robin, M., Paintal, S., Pote, B., Hruby, V., Freeman, C., "Iodine Plasma Propulsion Test Results at 110 kW," IEEE Transactions on Plasma Science, Special Issue - Plasma Propulsion, Vol. 43, No. 1, pp. 141148 (2015). doi: http://arc.aiaa.org/doi/abs/10.1109/TPS.2014.2367417

22 Szabo, J., Pote, B., Paintal, S., Robin, M., Hruby, V., "Iodine Fueled Plasma Generator System," US8610356 B2, 2013.

23 Dankanich, J., Calvert, D., Kamhawi, Hl, Hickman, T., Szabo, J., Byrne, L., The Iodine Satellite (iSat) Project Development Towards Critical Design Review," IEPC 2015-303, 34rd International Electric Propulsion Conference, Electric Rocket Propulsion Society, Kobe, Japan, July 4-10, 2015.

24 Polzin, K., Peeples, S., Mauro, S., Lewis, B., Seixal, J., Calvert, D., Dankanich, J., Kamhawi, Hl, Hickman, T., Szabo, J., Pote, B., Lee, L., "Propulsion System Development for the Iodine Satellite (iSAT) Demonstration Mission," IEPC 2015-09, 34rd International Electric Propulsion Conference, Electric Rocket Propulsion Society, Kobe, Japan, July 4-10, 2015.

25 Smith, T., Kamhawi, H., Hickman, T., Haag, T., Dankanich, J., Polzin, K., Byrne, L., Szabo, J., "Overview of NASA Iodine Hall Thruster Propulsion System Development," Space Propulsion 2016, Paper 3124773, Rome, Italy, May 2-6, 2016.

26 Tsay, M., Frongillo, J., Hohman, K., "Iodine-Fueled Mini RF Ion Thruster for CubeSat Applications," IEPC 2015-273, 34rd International Electric Propulsion Conference, Electric Rocket Propulsion Society, Kobe, Japan, July 4-10, 2015.

27 Haag, T., "Thrust Stand for High-Power Electric Propulsion Devices," Rev. Sci. Instrum. 62, 1186, 1991.

29 Wilson, E., An Introduction to Scientific Research, New York: McGraw Hill, 1952, pp. 272-274.

30 Hargus, W., and Reed, G., "The Air Force Clustered Hall Thruster Program," AIAA-2002-3678, 38th AIAA/ASME/SEA/ASEE Joint Propulsion Conference, Indianapolis, Indiana, July 7-10, 2002.

31 Beal, B, Gallimore, A, and Hargus, W., "The Effects of Clustering Multiple Hall Thrusters on Plasma Plume Properties," AIAA 2003-5155, 39th AIAA/ASME/SEA/ASEE Joint Propulsion Conference, Huntsville, AL, July 20-23, 2003.

32 Beal, B., Gallimore, A., Haas, J., and Hargus, W., "Plume Properties in the Plume of a Hall Thruster Cluster," Journal of Propulsion and Power, Vol. 20, No. 6, 2004, pp. 985-991.

33 Dankanich, J., Szabo, J., Pote, B., Oleson, S., Kamhawi, H., "Mission and System Advantages of Iodine Hall Thrusters," 50th AIAA/ASME/SAE/ASEE Joint Propulsion Conference, AIAA paper 2015-3905, Cleveland, Ohio, July 28-30, 2014.

34 Dankanich, J., Kamhawi, H., Szabo, J., Pote, B., "Iodine Electric Propulsion for Interplanetary Small Satellite Application," $1^{\text {st }}$ Interplanetary Small Satellite Conference, Pasadena, CA, June 20-21, 2013.

35 Colaprete, A, Andrews, D., Bellerose, J., Miotto, P., Genova, A., Foster, C. et al., "NEA Close Rendezvous and Operations Satellite," Global Space Exploration Conference, Washington D.C., May 22-24 2012, abstract GLEX-2012.03.3.6x12599

36 Woeppel, E., Balsamo, J., Fischer, K., East, M., Styborski, J., Roche, C., Ott, M., Scorza, M., Doherty, C., Trovato, A., Volk, C., Koontz, S., Bevilacqua, R., Swenson, C., "The Near Earth Object (NEO) Scout Spacecraft: A Low-cost Approach to In-situ Characterization of the NEO Population," AIAA 2014-1703, SpaceOps 2014 Conference, Pasadena, CA, May 4-9, 2014. 